\title{
Higher Education and Myanmar's Economic and Democratic Development
}

\section{Takao Kamibeppu and Roger Y. Chao, Jr.}

Takao Kamibeppu is professor of international education development at Fukuyama City University, Hiroshima, Japan. E-mail: t-kamibeppu@fcu.ac.jp. Roger Y. Chao Jr. is an independent higher education consultant, and was the former higher education consultant for UNESCO in Myanmar. E-mail: rylimchao@yahoo.com.

W ith Myanmar's economic and democratic transition in rapid progress, the higher education sector needs to reengineer itself. The November 2015 elections gave its mandate to a National League for Democracy (NLD) government. Efforts have to be made to enact higher education and private education laws, incorporate citizenship education, and increase engagement with the Association of Southeast Asian Nations (ASEAN).

\section{Evolving Education Legislation}

After 50 years of isolation, neglect, and underinvestment, Myanmar's higher education infrastructure (e.g. buildings, libraries, and laboratories), curriculum, research, and teaching capacity require substantial renovation, investment, and capacity building. Of the I70 public higher education institutions, under I3 different ministries, that comprise Myanmar's higher education, almost half are situated in Yangon (33) and Mandalay (36), and only ro universities can confer doctorate degrees. Furthermore, a significant number of these institutions actually offer vocational training or distance education, raising quality issues.

To address some of these issues, Myanmar's national education law was enacted in October 20I4. It was amended in June 2015 to incorporate the demands of protestors (e.g. students and civil society organizations), which slowed progress in drafting its subsector laws for higher and private education. Key higher education issues addressed in the law include the extent of university autonomy, the right to organize unions, and the university's right to formulate its own curriculum. Given the changing nature of higher education stakeholders, and the country's development needs, enacting and amending the national education law has been an evolving process characterized by inclusiveness, openness, and to a certain extent transparency, which are key features of a democratic government.

Transparency and good governance through a set of legal frameworks, and their implementation, help enhance the country's higher education reputation, especially with a clear higher education mandate including increased access, equity, quality, and relevance. Aside from economic considerations, however, Myanmar needs to consider its nation-building requirements and the contribution of higher education, through citizenship education, to ensure sustainable development and transition to democracy.

\section{UNIVERSITY-LED INITIATIVES?}

In spite of the uncertainty deriving from the absence of a higher education law, universities will be granted a degree of institutional autonomy, especially as they have been tasked to draft charters. Universities are under pressure to support the demands of a fast growing economy driven by local economic development and increasing direct foreign investment in the country's different sectors, including higher education.

Myanmar's higher education sector is now charged with the responsibility of producing enough graduates with the required skills, knowledge, and attitudes demanded by an economy increasingly connected to the global market. Universities need to reengineer themselves and their curriculum, to effectively conform to the requirements of Myanmar's fast changing economic and social environment. Within the proposed institutional autonomy framework, universities need human and financial resources along with much needed infrastructure, to effectively deliver globally skilled and competent human resources required by industry. Furthermore, quality standards need to be established through a national qualifications framework and an independent national quality assurance agency aligned with ASEAN and international practices.

Myanmar's universities, however, lack the capacity to undertake these changes, especially within an unfamiliar environment and a fairly new and vague institutional autonomy framework. Half a century of isolation and a constant lack of investment have taken their toll on the capacity of higher education institutions to adapt to regional and global standards and to the rapid changes of the country's economic and social environment. Although the international development community has contributed with technical assistance, capacity building, and even infrastructure development, a truly national higher education sector needs to take into consideration its own traditions, context, and needs, rather than transplant foreign models.

In addition, Myanmar universities need to engage in citizenship education to support social development, by inculcating the rights and responsibilities required to be a Myanmar, ASEAN, and global citizen. Under the above context and development, "proactive learning," which focuses on interactive and participatory learning led by faculty members, may provide an effective method to nurture citizenship and employability among students, and narrow the 
gap between the provision of higher education, the requirements of industry, and the country's economic and social development needs.

\section{Using ASEAN and International Frameworks}

Myanmar needs to conform to the requirements of its membership in ASEAN, and utilize its advantages. Aside from increasing regional economic integration, ASEAN, through the ASEAN University Network and SEAMEO RIHED (Southeast Asian Ministers of Education Organization/Regional Centre for Higher Education and Development), has taken a significant number of higher education initiatives that should help its member countries' higher education systems reach regional and international standards. These programs include establishing national qualifications frameworks, which will be referenced to the ASEAN Regional Qualifications Framework by 20I8; setting up the ASEAN Quality Assurance Network; and developing an ASEAN Credit Transfer System.

\section{After 50 years of isolation, neglect, and underinvestment, Myanmar's higher education infrastructure (e.g. buildings, libraries, and laboratories), curriculum, research, and teaching capacity require substantial renovation, investment, and capacity building.}

These higher education developments at the regional level do not stand alone. Other bilateral and multilateral higher education engagements also provide support for capacity development, infrastructure improvement, and guidance in international best practices. However, ASEAN provides a significant and tested framework in line with its policy of narrowing the developmental gap between its member countries, a strong regional basis for higher education cooperation, and a directive to establish not only the ASEAN Economic Community, but also the ASEAN Community, in the near future.

Higher education can be key to supporting the country's economic development and democratic transition. However, legal frameworks must be established and implemented, even if this remains an ongoing process. Support must be given to higher education institutions, especially within the proposed institutional autonomy framework, and universities need to be actively engaged in citizenship education to enhance nation building, reduce internal conflicts, and support the democratic transition. Finally, Myanmar's active engagement in ASEAN higher education initiatives provides support for capacity building, quality enhancement, mutual recognition, and, in time, meeting ASEAN higher education standards. Transparency, inclusion, and good governance remain key factors to improving Myanmar's higher education sector.

\section{Merging and Demerging Education Ministries in Malaysia}

\section{Richard SACK AND OMAR Jalloun}

Richard Sack is a consultant. He was formerly executive secretary of the Association for the Development of Education in Africa. E-mail: richardsack@gmail.com. Omar Jalloun is an assistant professor of international and comparative education at Taibah University, Madinah, Saudi Arabia. E-mail: ojalloun@taibahu.edu.sa. The work reported here is part of a larger study on the merger of education ministries, commissioned by the UNESCO Regional Center for Quality and Excellence in Education (RCQE) in Riyadh, Saudi Arabia.

$\mathrm{T}$ here is little research into the institutional/organizational underpinnings of education systems. Take, for example, the frequent phenomenon of mergers and demergers of education ministries. Many countries have several ministries of education: one for basic and secondary education (sometimes even one for each); another for higher education; yet another for vocational education. Over time, these ministries are merged, demerged, and reconfigured with sufficient frequency to provide ample meaning to the quote "it's déjà vu all over again" (and again and again).

Even though ministerial mergers and demergers are fairly common and pose similar challenges to all concerned, we were surprised to find only one study (in Zimbabwe) that directly addresses the issue. Studies on the reorganization of government structures are plentiful, but they do not address the particular issues of merger/demerger in education. And yet the abilities of education systems to meet expectations can be cruelly dependent on their organizational capabilities. In education, in particular, policy usually ends up being evaluated as implementation, and implementation is the work of organizational structures at all levels.

\section{Malaysia: A Case Study}

In Malaysia, the ministry of higher education (MoHE) was 